\title{
Pemindaian 3D Telapak Kaki dan Cara Menghasilkan Koordinat Konturnya untuk Keperluan Perancangan Sepatu Ortotik
}

\author{
Dwi Basuki Wibowo ${ }^{*}$, Gunawan Dwi Haryadi ${ }^{1}$, Eko Saputra² \\ ${ }^{1}$ Departemen Teknik Mesin, Fakultas Teknik, Universitas Diponegoro, Semarang \\ Jl. Prof. Sudarto, SH., Tembalang, Semarang \\ ${ }^{2}$ Jurusan Teknik Mesin, Politeknik Negeri Semarang \\ Jl. Prof. Sudarto, SH., Tembalang, Semarang \\ *E-mail: rmt.bowo@gmail.com
}

Diterima: 19-02-2021; Direvisi: 23-07-2021; Dipublikasi: 27-08-2021

\begin{abstract}
Abstrak
Pemindaian 3D telah banyak diterapkan di berbagai bidang kedokteran, forensic, anthropology, anthropometry, topography, hingga reverse engineering. Penelitian ini mengkaji pemindaian 3D telapak kaki dan cara menghasilkan koordinat kontur xyz-nya. Alat pemindai yang digunakan adalah 3D scanner for foot orthotic buatan Vismach Technology China yang dilengkapi software untuk menghasilkan luaran berekstensi standard dxf/stl/wrl/obj/ply/asc. Koordinat kontur xyz diperoleh dari software AutoCAD dan MS Excel yang sudah terdapat coding khusus untuk membaca koordinat dari file AutoCAD. Struktur data koordinat xyz di MS Excel berbentuk baris pertama menyatakan ujung jari jempol dan baris terakhir menyatakan ujung tumit. Dari hasil koordinat ini evaluasi panjang dan lebar telapak kaki, menentukan ukuran sepatu, mendesain sepatu orthotic bagi penderita flat foot dan calcanea spur, dan pembagian area telapak kaki untuk pengukuran beban menjadi mudah dilakukan. Disamping itu luaran scanner berbentuk 3D mesh dan citra berekstensi stl bermanfaat dalam memodelkan kontak telapak kaki menggunakan MEH serta merancangbangun prototype sol sepatu dengan bantuan software SOLIDWORKS dan Rhinoceros.
\end{abstract}

Kata kunci: pemindaian 3D; telapak kaki; koordinat kontur xyz; sepatu orthotic

\begin{abstract}
$3 D$ scanning has been widely applied in various fields of medicine, forensic, anthropology, anthropometry, topography, to reverse engineering. The study examined $3 D$ scanning of the soles of the feet and how to generate their xyz contour coordinates. The scanner used a 3D scanner for foot orthotic made by Vismach Technology China equipped with software to generate the standart $\mathrm{dxf} / \mathrm{stl} / \mathrm{wrl} / \mathrm{obj} /$ ply/asc extension. Xyz contour coordinates are obtained from AutoCAD and MS Excel software which already have special coding to read the coordinates of AutoCAD files. The xyz coordinate data structure in MS Excel is in the form of the first row declaring the fingertip of the thumb and the last row declaring the heel tip. From the results of these coordinates evaluation of the length and width of the soles of the feet, determining the size of the shoes, designing orthotic shoes for people with flat foot and calcanea spur, and the division of the sole area of the foot for weight measurement becomes easy to do. In addition, the outer scanner shaped 3D mesh and imagery with stl extension is useful in modeling the contact of the soles of the feet using MEH and designing prototype shoe soles with the help of Solidworks and Rhinoceros software.
\end{abstract}

Keywords: 3D scan; sole; xyz contour coordinate; orthotic shoe

\section{Pendahuluan}

Dewasa ini perkembangan teknologi pemindaian (scanning) berlangsung sangat pesat.Di bidang kedokteran, untuk mengetahui kelainan pada tulang yang semula menggunakan rontgen kini bisa menggunakan Computed Tomography scan (CT scan) atau Magnetic Resonance Imaging (MRI). Teknologi pemindaian juga telah diaplikasikan untuk mengkaji berbagai modus kejahatan (forensic study) [1], identifikasi spesies binatang purba (anthropology study) [2], identifikasi jenis kelamin dan postur tubuh (anthropometry study) [3], menyusun peta kontur suatu daerah (topography map) [4], hingga keperluan untuk merancang ulang suatu produk mesin (reverse engineering) [5]. Teknologi pemindaian ini umumnya disebut pemindaian tidak berbeban (unloaded scanning) [6]. 
Dwi Basuki Wibowo dkk /Jurnal Rekayasa Mesin

p-ISSN: 1411-6863, e-ISSN: 2540-7678

Vol.16|No.2|165-171|Agustus|2021

Teknologi pemindaian berbeban (loaded scanning) juga berlangsung sangat pesat.Diantaranya yaitu pemindaian tubuh manusia yang diduga mengidap flu burung, beban arus listrik suatu unit di industri manufaktur, distribusi panas di suatu mesin dan panel listrik, pemindaian jejak telapak kaki untuk mengidentifikasi jenis telapak kaki (footprint scanning) [7] dan distribusi tekanan di telapak kaki (foot pressure distribution) [8]. Hasil keluaran pemindaian berbeban ini berupa citra berbentuk warna-warna dimana warna merah menyatakan beban atau deformasi paling besar sedangkan warna biru tua paling kecil. Hasil pemindaian tidak berbeban ada juga yang dinyatakan dalam bentuk gradasi warna seperti citra 3D telapak kaki pada Gambar 1.

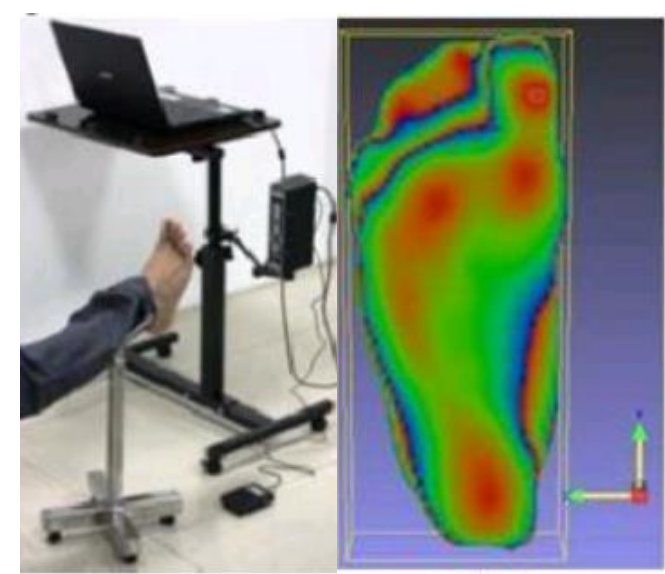

Gambar 1. Pemindaian 3D telapak kaki [9]

Pemindaian 3D telapak kaki seperti pada Gambar 1 dilakukan menggunakan 3D scanner for foot orthotic [9]. Luaran alat bisa berupa pandangan 3D plantar telapak kaki dalam bentuk warna-warna dimana warna merah menunjukkan koordinat $\mathrm{z}$ area telapak kaki tersebut besar atau lebih cembung dibandingkan area lainnya, 3D plantar telapak kaki dalam bentuk kontur untuk cetakan negatif sol sepatu, dan model positif 3D yang memperlihatkan kontur cetakan sol sepatu. Paper ini membahas pemindaian 3D telapak kaki yang sangat berguna untuk merancang sepatu orthotic.

Umumnya untuk memperoleh kontur sol sepatu orthotic yang disesuaikan dengan kontur telapak kaki dilakukan dengan cara mencetakkan telapak kaki di material gypsum. Penggunaan 3D scanner untuk memperoleh kontur telapak kaki merupakan teknologi baru yang telah digunakan oleh para peneliti sebelumnya, diantaranya Telfer et al. [10] dan Stankovic et al. [11]. Baik Telfer maupun Stankovic keduanya menggunakan 3D scanner modern yang beresolusi tinggi yang dilengkapi dengan object oriented program, sehingga mudah dalam melakukan editing permukaan object. Pada penelitian ini dibahas cara menghasilkan koordinat xyz kontur telapak kaki yang tidak disediakan di perangkat 3D scanner for foot orthotic [9]. Metode menghasilkan struktur data koordinat xyz yang dibahas di sini sangat penting tidak hanya pada kontur telapak kaki tetapi juga untuk kontur 3D lainnya.

\section{Metode Penelitian}

\subsection{Metode Pemindaian}

Pada penelitian ini scanner yang digunakan mengaplikasikan teknologi active stereo vision 3D dengan proyeksi cahaya putih tanpa laser sehingga aman untuk mata. Pengambilan pindainya cepat (0.1-0.2 detik), hasil 3D mesh-nya bersih, dan akurasi liniernya $\pm 1,0 \mathrm{~mm}$. Software alat ini menghasilkan luaran berekstensi dxf/stl/wrl/obj/ply/asc [9]. 
Dwi Basuki Wibowo dkk /Jurnal Rekayasa Mesin

p-ISSN: 1411-6863, e-ISSN: 2540-7678

Vol.16|No.2|165-171|Agustus|2021

Untuk memperoleh hasil yang jelas cara pemindaian seperti pada Gambar 1 tidak bisa dilakukan karena pengaruh pencahayaan ruangan. Sebagai gantinya telapak kaki dan alat scanner diletakkan pada kotak pemandu yang diberi warna hitam di bagian dalam, bisa dilihat pada Gambar 2(a). Agar telapak kaki lurus saat dipindai dibuat penyangga dan dipantau kelurusannya oleh kamera seperti pada Gambar 2(b).

Subjek diminta duduk dan menelonjorkan salah satu kakinya lurus di tempat yang telah disediakan. Bagian bawah kaki dimasukkan dalam tabir hitam hingga menyentuh batang tegak yang dapat digeser sesuai lebar telapak kaki. Kedua batang tegak tersebut ditujukan untuk mencegah telapak kaki miring ke kanan/kiri saat dipindai. Subjek juga diminta menegakkan telapak kakinya hingga menyentuh batang lurus mendatar di bagian atas yang dapat digeser naik/turun. Batang tersebut ditujukan untuk mencegah telapak kaki tidak melengkung ke depan saat dipindai.

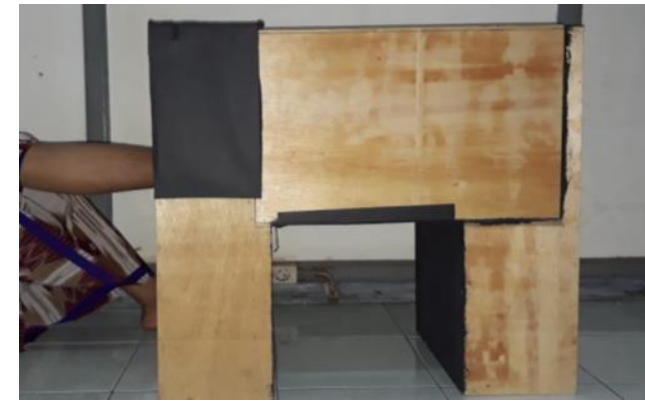

(a)

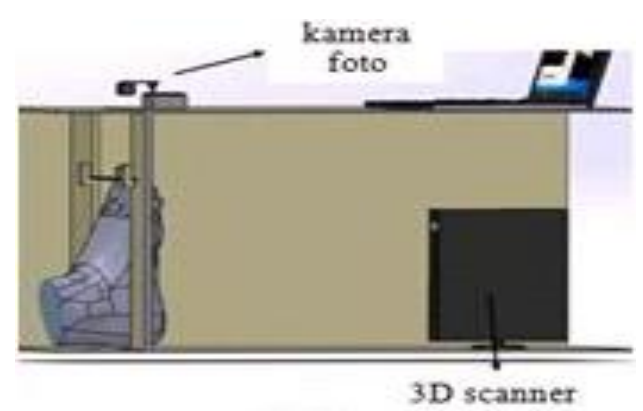

(b)

Gambar 2. (a) Kotak pemandu pemindaian 3D telapak kaki dan (b) Pemantau kelurusan telapak kaki

Pengaturan telapak kaki subjek sebelum dipindai dipandu oleh operator melalui kamera foto. Subjek juga bisa melihat posisi telapak kakinya diawasi komputer yang diletakkan di atas kotak pemandu. Setelah telapak kaki subjek dianggap lurus operator akan mengeklik "tombol" scan di monitor. Hasil pemindaian telapak kaki kanan subjek diperlihatkan seperti pada Gambar 3. Setelah file disimpan, pemindaian dapat dilakukan untuk telapak kaki kiri.

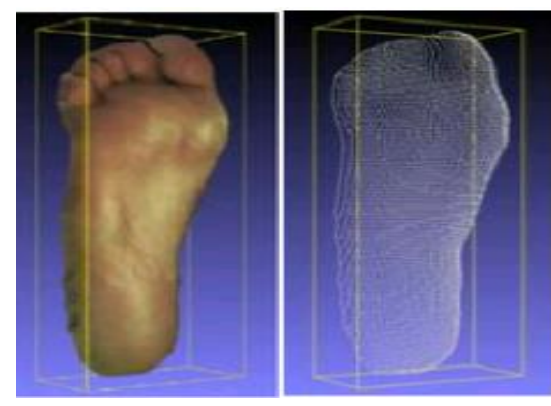

(a)

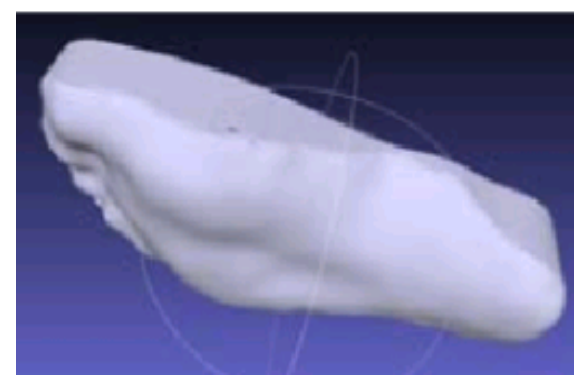

(b)

Gambar 3. Hasil pemindaian 3D telapak kaki, (a) Tampak bawah dan (b) Tampak isometri

\subsection{Cara Menghasilkan Koordinat Kontur Telapak Kaki}

Mendeteksi koordinat xyz telapak kaki dilakukan menggunakan software AutoCAD dan MS Excel. Caranya sebagai berikut:

1) Buka file hasil scan 3D berekstensi dxf di software AutoCAD

2) Buka MS Excel yang sudah terdapat coding khusus untuk membaca koordinat dari file AutoCAD, seperti nampak pada Gambar 4 
Dwi Basuki Wibowo dkk /Jurnal Rekayasa Mesin p-ISSN: 1411-6863, e-ISSN: 2540-7678

Vol.16|No.2|165-171|Agustus|2021

3) Klik import AutoCAD Coordination akan membuka software AutoCAD dan klik "nama file-nya", otomatis akan terbuka MS Excel yang menampilan koordinat xyz kontur telapak kaki.

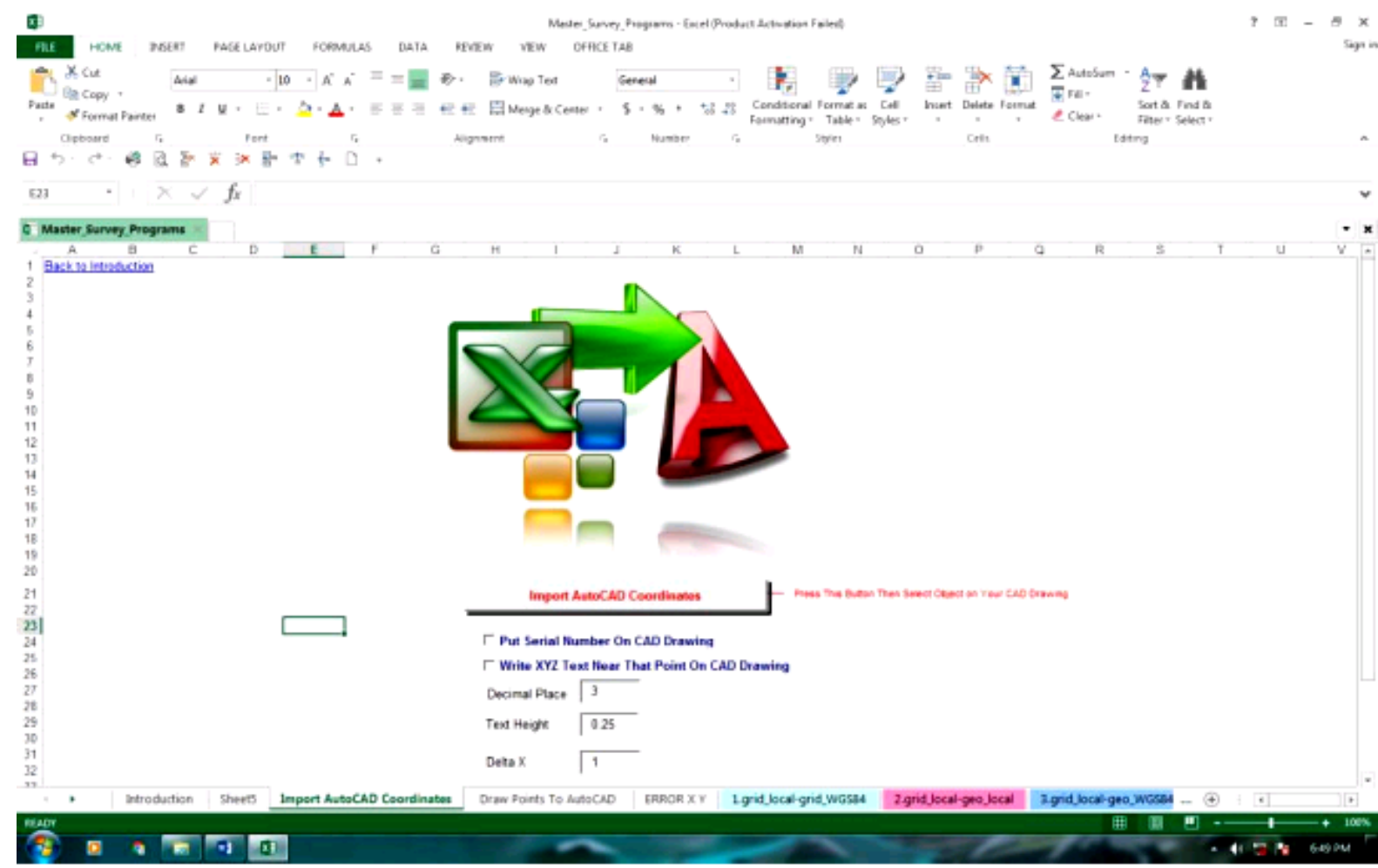

Gambar 4. MS Excel coding koordinat AutoCAD

\section{Hasil dan Pembahasan}

Struktur data koordinat xyz telapak kaki di MS Excel diperlihatkan pada Gambar 5. Umumnya jumlah data terdiri dari \pm 4000 baris. Baris pertama menyatakan ujung jari jempol dan baris terakhir menyatakan ujung tumit. Baris data pada koordinat y yang sama menunjukkan lokasi koordinat $\mathrm{x}$ sepanjang lebar telapak kaki dengan jarak antar titik koordinat $\Delta \mathrm{x}=2 \mathrm{~mm}$. Baris data berikutnya dengan perbedaan koordinat y sebesar $\Delta \mathrm{y}=2 \mathrm{~mm}$ menunjukkan lokasi koordinat $\mathrm{x}$ sepanjang lebar telapak kaki berikutnya di bawahnya. Jarak antara 2 titik berdekatan dalam arah z pada koordinat xy tertentu juga sebesar $\Delta \mathrm{z}=2 \mathrm{~mm}$.

\begin{tabular}{ccrc}
\hline SNo. & $x$ & $y$ & $z$ \\
\hline 1 & 2.753229 & -129.049 & 143.6826 \\
2 & 4.753229 & -129.049 & 145.0586 \\
3 & 6.753229 & -129.049 & 146.1786 \\
4 & 8.753229 & -129.049 & 146.8859 \\
5 & 10.75323 & -129.049 & 147.1779 \\
\hline 4183 & 38.75323 & 106.9508 & 149.4875 \\
4184 & 40.75323 & 106.6545 & 148.3796 \\
4185 & 42.75323 & 106.136 & 147.153 \\
4186 & 32.75323 & 107.4693 & 149.592 \\
\hline
\end{tabular}

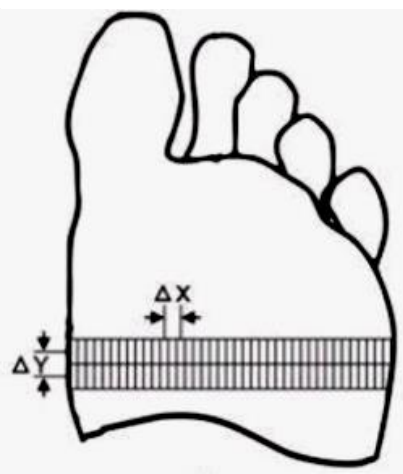

Gambar 5. Struktur data koordinat xyz 
Dwi Basuki Wibowo dkk /Jurnal Rekayasa Mesin

p-ISSN: 1411-6863, e-ISSN: 2540-7678

Vol.16|No.2|165-171|Agustus|2021

Hasil koordinat xyz kontur telapak kaki ini jika di-plot di MS Excel terlihat seperti pada Gambar 6. Untuk keperluan analisis jenis telapak kaki (high arch, normal, flat foot) saat kondisi tidak berbeban dengan metode Cavanagh sumbu telapak kaki pada bidang yx harus digeser ke bawah melalui jari kaki ke 2 [12]. Untuk mengestimasi deformasi tumit saat subjek berdiri sumbu y telapak kaki pada bidang yz harus digeser ke koordinat $\mathrm{y}=0$ [13].

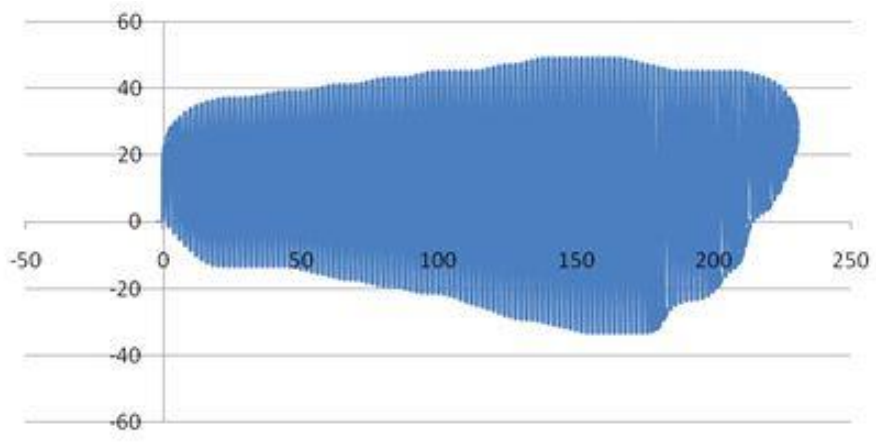

(a)

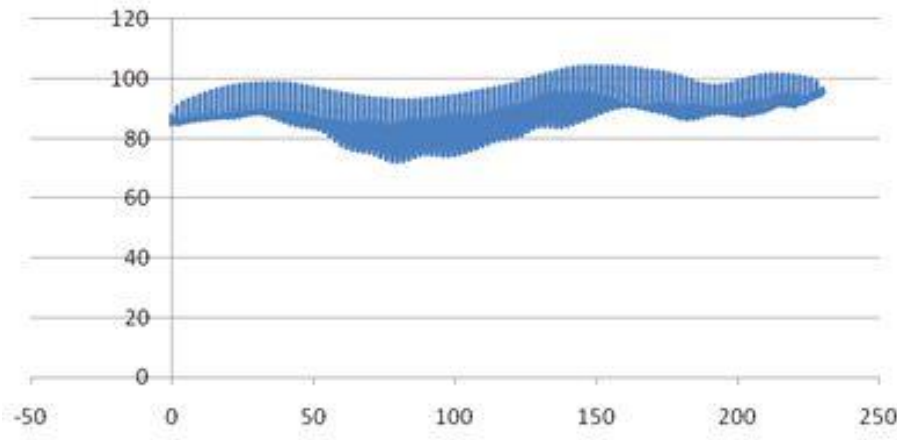

(b)

Gambar 6. Penggambaran di MS Excel (a) Pandangan yx dan (b) Pandangan yz

Pemeriksaan kelurusan telapak kaki saat dipindai juga mudah dilakukan. Pada Gambar 6(b) terlihat telapak kaki subjek masih menekuk ke depan sehingga pemindaian harus diulangi. Evaluasi panjang dan lebar telapak kaki (FL-foot length dan FW-foot width) untuk validasi terhadap pengukuran menggunakan footprint scanner juga mudah dilakukan. Dimana FL adalah perbedaan jarak y baris terakhir dengan baris pertama dan, FW adalah perbedaan jarak $\mathrm{x}$ terbesar dan terkecil. Nilai FL dan FW pada kondisi tidak berbeban sedikit lebih kecil dibandingkan hasil footprint [14].

Evaluasi hasil pemindaian 3D telapak kaki dan generate koordinat konturnya ini dapat digunakan juga untuk menentukan ukuran sepatu berdasar data-data FL dan FW [15], mendesain sepatu orthotic [16-17], dan pembagian area telapak kaki untuk peletakan sensor pada pengukuran beban saat subjek berdiri maupun berlari [18]. Selain itu juga berguna untuk mengestimasi tempat kedudukan titik-titik koordinat $\mathrm{z}$ terbesar di sepanjang telapak kaki, bisa dilihat pada Gambar (7) yang bermanfaat dalam melakukan pemodelan Metode Elemen Hingga (MEH) [19]. 


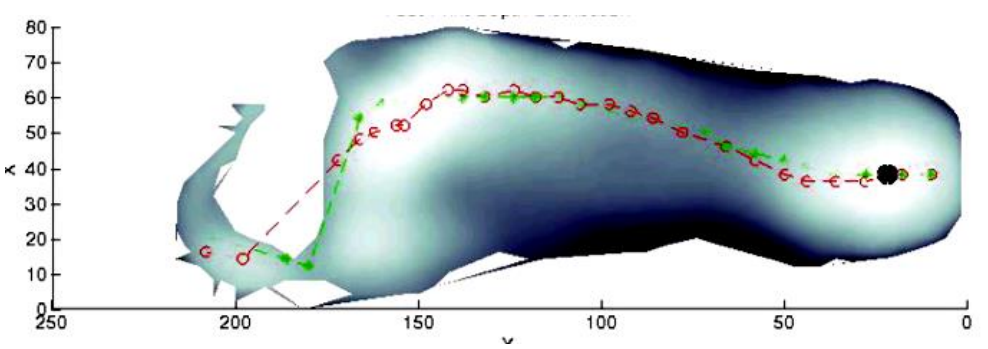

Gambar 7.Tempat kedudukan titik-titik koordinat $\mathrm{z}$ terbesar di sepanjang telapak kaki

\section{Kesimpulan}

Penggunaan 3D scanner for foot orthotic dengan luaran yang dapat diolah oleh berbagai software memudahkan menghasilkan koordinat kontur xyz untuk berbagai keperluan. Pelacakan koordinat lokasi anterior dan posterior serta kontur dan batas lengkungan di medial arch untuk mendesain sisipan di medial arch sol sepatu orthotic menjadi sangat mudah dilakukan. Memvariasikan tinggi hak sepatu dan luas kontak sol sepatu untuk mengurangi tekanan di area tumit bagi penderita calcanea spur juga mudah dilakukan dibandingkan cara manual mencetakkan telapak kaki di cetakan gibsum. Disamping itu hasil 3D mesh luaran scanner yang bersih sangat bermanfaat untuk pemodelan kontak telapak kaki dengan landasan menggunakan MEH baik saat berjalan maupun berlari Bentuk luaran file berekstensi stl juga sangat membantu dalam mendesain dan membuat prototype sol sepatu dengan bantuan software SOLIDWORKS dan Rhinoceros. Secara umum pemindaian 3D ini juga terbukti sangat membantu dalam melakukan proses desain. Banyak produk-produk baru tercipta dalam waktu singkat berkat reverse engineering yang memanfaatkan teknologi pemindaian 3D ini.

\section{Daftar Pustaka}

[1] Mujid, R. Prediksi Berat dan Tinggi Badan Manusia Indonesia Dari Hasil Jejak Telapak Kaki Untuk Keperluan Forensik. Tugas Akhir S1, Universitas Diponegoro, Semarang, 2016.

[2] Crompton, R.H.; Pataky, T.C.; Savage, R.; D'aout, K.; et al. Human-like external function of the foot, and fully upright gait, confirmed in the 3.66 million year old Laetolihominin footprints by topographic statistics, experimental footprintformation and computer simulation, J. R. Soc. Interface 9, 707-719 (2012)

[3] Brolin, Erik. Anthropometric diversity and consideration of human capabilities. Thesis for the degree of doctor of philosophy. Dep. Of Product and Production Development, Division of Production Systems, Chalmers University of Technology, Gothenberg, Sweden 2016

[4] Gonzalez, Rafael C.; Woods, Richard E.; and Eddins, Steven L. Digital Image Procesing Using MATLAB. Second Edition. Gatesmark Publishing. A Division of Gatesmark, LLC (2009)

[5] Yao, A.W.L. Applications of 3D scanning and reverse engineering techniques for quality control of quick response products. The international journal of advanced manufacturing technology, 26(11-12), pp.1284-1288 (2005).

[6] Wibowo, DB.; Dwi Haryadi, GD.; Widodo, A; and Rahayu, SP. Correlation of loaded and unloaded foot area with arch index in younger flatfoot. ICME2016 International Conference on Mechanical and Manufacturing Engineering, August 1-3, 2016

[7] Haryadi, GD.; Wibowo, DB.; Widodo, A.; Suprihanto, A. Comparison of ratio loaded and unloaded foot area of flat foot and healthy foot in younger adults. MATEC Web of Conferences 159, 02019 (2018) 
Dwi Basuki Wibowo dkk /Jurnal Rekayasa Mesin

p-ISSN: 1411-6863, e-ISSN: 2540-7678

Vol.16|No.2|165-171|Agustus|2021

[8] Periyasamy, R., et al. Preliminary investigation of foot pressure distribution variation in men and women adults while standing, The Foot 21 (2011) $142-148$

[9] ScanPod3D. 3D Scanner Mini and Scansoft for Foot Orthotic. Vismach Technology Ltd., 2013. wWw.scanpod3d.com

[10] Telfer, S. and Woodburn, J. The use of 3D surface scanning for the measurement and assessment of the human foot. Journal of Foot and Ankle Research 2010, 3:19

[11] Stankovic, K.; Booth, BG.; Danckaers, F.; Burg, F.; et al. Three-dimensional quantitative analysis of healthy foot shape: a proof of concept study. Journal of Foot and Ankle Research (2018) 11:8

[12] Peter R. Cavanagh and Mary M. Rodgers, The Arch index: a useful measure from footprints, J. Biomechanics Vol. 20, No. 5, pp. 547-551, (1987)

[13] Wibowo, DB.; Suprihanto, A.; Widodo, A.; Haryadi, GD. Estimation of calcaneal deformation while standing from the boolean operation between 3D and footprint image and its comparison with lateral x-ray. MATEC Web of Conferences 204, 07001 (2018)

[14] Wibowo, D.B.; Suprihanto, A.; Haryadi, G.D. Development of Prototype Scanners for Diagnosis of Foot Anomalies. In Higher Education Applied Research Report (PTUPT); DRPM DIKTI: Jakarta, Indonesia, 2018

[15] Boehm, R. The foot \& the shoe: Measurement \& size. DARCO (Europe) GmbH. June 2015

[16] Wibowo, DB.; Harahap, R.; Widodo, A.; Haryadi, GD.; Mochammad, A. The effectiveness of raising the heel height of shoes to reduce heel pain in patients with calcanea spur. J. Phys. Ther. Sci. 29: 2068-2074, 2017

[17] Wibowo, DB.; Widodo, A.; Haryadi, GD.; Caesarendra, W.; Harahap, R. Effect of in-shoe foot orthoses contour on heel pain due to calcaneal spur. Appl. Sci.2019, 9, 495; doi:10.3390/app9030495

[18] Yung-Hui, L.; Wei-Hsien, H. Effects of shoe inserts and heel height on foot pressure, impact force, and perceived comfort during walking, Applied Ergonomics 36 (2005) 335-362

[19] Pinto, VC.; Ramos, NV.; Vaz, MAP.; Marques, MA. 3D modeling for FEM simulation of an obese foot. ResearchGate. Conf. Paper, January (2010) 